\title{
EFICIÊNCIA DA EQUOTERAPIA EM PRATICANTES COM SÍNDROME DE DOWN: REVISÃO DE LITERATURA
}

\section{Vinícius Spagnol Regasson'; Jaqueline Stefanello Garlet ${ }^{1}$; Nathaly Marin Hernandez ${ }^{2}$}

\section{RESUMO}

Introdução: Os indivíduos com síndrome de Down apresentam características peculiares da anatomia, sendo assim se faz necessário que eles tenham consciência de suas condições, para que procurem os melhores métodos para combater e/ou reduzir seus agravos. Objetivo: Analisar os materiais disponíveis na literatura, e assim verificar os efeitos que a equoterapia pode fornecer aos indivíduos com síndrome de Down. Metodologia: Foi feita uma revisão bibliográfica nas bases de dados online, buscando a eficiência da equoterapia em praticantes com síndrome de Down. Utilizando-se dos descritores e operadores boleanos: terapia assistida por cavalo OR equoterapia AND síndrome de Down. Dentro os critérios de inclusão temos: artigos que estejam disponíveis em língua portuguesa e gratuitamente para acesso, já como critério de exclusão, inclui-se: estudos que fossem revisão bibliográficas. Resultado: A pesquisa foi realizada em seis base de dados diferentes, contudo houveram apenas resultados positivos nas bases SciELO e LILACS, após a aplicação dos critérios de inclusão e exclusão teve-se a somatória de seis artigos. Os estudos trouxeram principalmente uma população amostral de crianças onde os benefícios variaram desde adaptação rítmica e ajustes tônicos até aquisições motoras, fortalecimento muscular e melhora do déficit de força dos membros superiores e inferiores, entre outros. Conclusão: Conforme os estudos encontrados para essa revisão, pode-se concluir que a equoterapia tem grande eficiência na melhora dos praticantes com síndrome de Down. O tratamento equoterápico tem grande influência no ajuste tônico, nas reações de equilíbrio, melhora postural, controle de tronco e normalização de tônus muscular. Mas carece de informações e estudos, o que ressalta a importância da realização de novas pesquisas na área da equoterapia, para assim beneficiar os praticantes em geral.

Palavras-chave: Terapia assistida por cavalo; Trissomia do cromossomo 21; Fisioterapia.

\section{INTRODUÇÃO}

A equoterapia, uma prática regulamentada pela lei 13830/19, utiliza o cavalo como instrumento terapêutico e educacional em uma abordagem 
interdisciplinar que envolve o desenvolvimento biopsicossocial dos praticantes.

Constituída por uma equipe multiprofissional que envolve, psicólogo, fisioterapeuta e um profissional de equitação na sua equipe mínima de atuação (BRASIL, 2019). O Conselho Federal de Fisioterapia e Terapia Ocupacional (COFFITO) dispõem a equoterapia aos fisioterapeutas e terapeutas ocupacionais como um recurso terapêutico de caráter não corporativo, transdisciplinar aos tratamentos e que buscam estimular mecanismos naturais de prevenção de agravos e recuperação da saúde por meio de tecnologias eficazes e seguras (BRASIL, 2008).

Silva (2014), traz que a equoterapia utiliza do cavalo como um instrumento cinesioterapêutico, sendo esse um agente pedagógico e de inserção social. A atividade contribui para o desenvolvimento neuropsicomotor e melhoramento muscular, relaxamento e aperfeiçoamento da coordenação e equilíbrio, uma vez que a terapia busca o desenvolvimento psicológico e físico necessários no desempenho dos praticantes com necessidades educativas especiais, estimulando-os a usar sua capacidade de autorrealização.

Uzun (2005) afirma que, a equoterapia tem sua eficiência devido, principalmente, a andadura do cavalo que se caracteriza por ser similar ao movimento da marcha humana, o movimento no plano vertical, em movimentos para cima e para baixo, no plano horizontal, em movimentos para a direita e para a esquerda e movimentos para frente e para trás, se caracteriza como um movimento tridimensional que é transmitido do cavalo ao praticante, sendo necessário assim, diversos ajustes tônicos enquanto o praticante está em montaria.

A síndrome de Down (SD) é uma condição genética causada pela trissomia do cromossomo 21 que leva a uma distribuição cromossômica inadequada durante a fase de meiose. Indivíduos normais possuem 46 cromossomos, que estão divididos em 23 pares, em pessoas com SD, o par de número 21 possui um cromossomo a mais, resultando em 47 cromossomos (TORQUATO et al., 2013). 
O artigo de Espindula et al. (2014), descreve que indivíduos com SD apresentam características peculiares da anomalia, das quais as principais e mais frequentes são hipotonia muscular, menor consistência em tarefas de precisão, atraso no desenvolvimento intelectual, além de alterações das características físicas, visíveis e identificáveis. O controle postural e o equilíbrio são elementos importantes na realização de funções motoras, sendo a estabilidade postural importante para a aquisição de habilidades complexas (ESPINDULA et al., 2014).

Espindula et al. (2014), salienta que, dentre os tratamentos propostos para a população com SD, existe a equoterapia que possui estratégias que auxiliam o controle postural e, consequentemente, proporcionam melhoras nas atividades diárias e na independência pessoal.

Perante a isso se torna de grande valia que, as pessoas que tenham SD tenham consciência de suas condições, e que, a equoterapia pode ser um recurso potencialmente valioso no combate e/ou redução de agravos ocasionados pela síndrome. Assim sendo, o perante estudo tem intuito de verificar os materiais com análises científicas disponíveis na literatura, ao qual verifiquem e/ou apontem os efeitos que a equoterapia pode fornecer aos indivíduos com SD.

\section{METODOLOGIA}

Este estudo trata-se de uma revisão de literatura que busca os efeitos da equoterapia em praticantes com SD, onde foi feita uma pesquisa através de bases de dados online utilizando-se dos descritores e operadores boleanos: terapia assistida por cavalo OR equoterapia AND síndrome de Down, os descritores foram utilizados tanto juntos quanto separadamente, visando maximizar e ampliar o espectro da pesquisa. Dentro os critérios de inclusão temos: artigos que estejam disponíveis em língua portuguesa e gratuitamente para acesso, já como critério de exclusão, inclui-se: estudos de revisão, teses,

1Vinícius Spagnol Regasson e Jaqueline Stefanello Garlet - Académicos do Curso de Fisioterapia da Universidade Franciscana - viniciusregasson@hotmail.com jaquelinegarlet15@outlook.com 
monografias, dissertações, comentários e anais de eventos. Dentre os estudos que contemplaram os critérios de inclusão e exclusão, foram então selecionados para leitura na íntegra e assim estabeleceu-se um roteiro para o estudo dos artigos.

\section{RESULTADOS}

A pesquisa foi realizada em seis bases de dados diferentes, entre elas: SciELO, LILACS, MEDLINE, IBECS, PubMed e ScienceDidect, contudo apenas as bases SciELO e LILACS apresentaram artigos que fossem compatíveis com os critérios de inclusão, na base de dados SciELO foram encontrados dois artigos, e na base LILACS foram encontrados sete, no entanto, dois desses já estavam presentes na base anterior. Dentre os sete artigos resultantes foram aplicados os critérios de exclusão, resultando no total de seis artigos para análise e literatura na íntegra, já que um dos estudos se trata de uma revisão integrativa.

\section{DISCUSSÃO}

O estudo feito por Torquato et al. (2013), teve como objetivo verificar a aquisição de marcos motores em crianças com SD que realizam a equoterapia e fisioterapia convencional, e descrever a aquisição de marcos motores, equilíbrio estático, equilíbrio dinâmico, força muscular e tempo de tratamento. Trata-se de um estudo do tipo transversal, composto por 33 crianças com SD de ambos os sexos, com idade entre 4 a 13 anos. As crianças foram divididas em dois grupos, no grupo 1 foram incluídas 19 crianças que realizaram a equoterapia no RPMON e no grupo 2 participaram 14 crianças que realizavam fisioterapia convencional no solo na APAE de Mogi das Cruzes. Sendo assim, questionários biopsicossociais da escala de desenvolvimento motor (EDM) e da escala de força de Daniels foram aplicados.

'Vinícius Spagnol Regasson e Jaqueline Stefanello Garlet - Académicos do Curso de Fisioterapia da Universidade Franciscana - viniciusregasson@hotmail.com jaquelinegarlet15@outlook.com 
O estudo salientou que as crianças com SD, apresentam atraso no desenvolvimento motor, e a equoterapia e a fisioterapia convencional influenciaram na aquisição de marcos motores, sendo mais evidente no grupo da fisioterapia (TORQUATO et al., 2013).

Por fim, Torquato et al. (2013), ressalta que para que o desenvolvimento motor ocorra, as crianças precisam passar por momentos de experimentação e erro, aprimorando as habilidades motoras. Assim, o tratamento equoterápico tem grande influência nesse aspecto, uma vez que na equoterapia observa-se um ajuste tônico, marcado pelo movimento automático de adaptação ritmado, o que facilita as informações proprioceptivas.

No estudo feito por Bevilacqua et al. (2016), onde se objetiva avaliar a variabilidade da frequência cardíaca (VFC) em 6 crianças entre 10 e 14 anos $_{2}$ com SD, submetidas a 5 sessões de equoterapia, denota-se que, a equoterapia não proporcionou aumento da VFC. Isso, supondo-se que, por não ter sido incluso a prática de atividade ou exercício físico durante a montaria, resultou-se no déficit de atenção dos praticantes, tendo efeito direto na redução da VFC.

Copetti et al. (2007), busca verificar o efeito da equoterapia no comportamento angular do tornozelo e joelho de crianças com SD que apresentavam alterações na curva de angulação do tornozelo durante a marcha. O estudo investigou três crianças com trissomia 21, do sexo masculino, com média de idade de 7,3 anos. Adotou-se como período de intervenção treze sessões, em que cada uma teve duração de cinquenta minutos, incluindo o tempo de aproximação, monta e encerramento, com intervalo de sete dias entre elas.

O estudo analisou o comportamento angular do tornozelo e joelho após a intervenção, havendo uma diferença significativa para o tornozelo, predominantemente na fase de balanço e progressão do toque inicial do pé para todos os sujeitos, o que também foi observado em estudo similar, refletindo o aumento na dorsiflexão plantar nessa fase. Para a articulação do joelho, diferenças estatisticamente significativas foram verificadas em 
momentos distintos do ciclo, não apresentando uma tendência observável (COPETTI et al, 2007).

Copetti et al. (2007), salientam que a posição de montaria permite uma variedade de estímulos que desenvolvem reações de equilíbrio, melhora postural, controle de tronco e normalização de tônus muscular. Ocasionando fortalecimento dos músculos dorsiflexores resultante da posição do pé no estribo, durante as sessões, favorecendo a dorsiflexão e eversão do pé.

Dentre os achados nos estudos anteriores, Proença et al. (2020) traz diversos benefícios que corroboram com estes. É relatado que, a equoterapia associada a fisioterapia, tem uma influência direta na aquisição motora, já que a técnica estimula diversos sistemas, como, proprioceptivo, somatossensorial, vestibular e visual. Desses, os últimos três estão relacionados diretamente ao déficit de equilíbrio em crianças com SD, já que quando tais sistemas apresentam-se afetados e/ou alterados resultam na oscilação corporal devido a dificuldade de captar informações sensoriais de propriocepção. A prática da equoterapia é amplamente benéfica para os praticantes, contudo não se é alcançado uma melhora considerada normal para a idade cronológica dos indivíduos.

Proença et al. (2020) relata que, o próprio ato de cavalgar por si só gera estímulos ao praticante, mas algumas manobras associadas à atividade podem aumentar essa quantidade de estímulos. Solicitar ao paciente que, feche os olhos, retire os pés do estribo, ficar em alguma posição em cima do cavalo ou até utilizar o estribo para ficar em posição ortostática, resulta no fortalecimento muscular e melhoramento do déficit de força de membros superiores e inferiores.

Objetivou-se no estudo de Espindula et al. (2014), verificar por meio da eletromiografia qual o melhor material de montaria e posicionamento dos pés para o recrutamento da musculatura de tronco de crianças com SD submetidas a tratamento equoterapêutico. Caracteriza-se por ser uma pesquisa de campo com delineamento transversal e caráter exploratório, sendo esse um estudo 
piloto. Participaram de todas as etapas do trabalho cinco meninos, com idade entre 7 e 16 anos com diagnóstico de SD e fisioterapêutico de hipotonia muscular global. Foram aplicadas quatro sessões de equoterapia de 30 minutos, uma vez por semana, com materiais de montaria diferentes, sela, manta e posicionamento dos pés fora dos estribos ou nos estribos. Sendo utilizado um cavalo da raça Árabe com andadura a passo e engajamento de patas de forma a transpistar, antepistar e sobrepistar, altura de $1,50 \mathrm{~cm}$ da cernelha até o chão, 16 anos de idade, apresentando boa saúde física e psíquica e temperamento dócil.

Por fim, a montaria com manta e pés fora do estribo comparada com outros tipos de montaria analisados promoveu mais recrutamento de unidades motoras, sendo, portanto, uma boa escolha de material de montaria na equoterapia para praticantes com SD, uma vez que estes apresentam hipotonia. Sendo assim, a utilização desse tipo de material de montaria, com pés fora do estribo, provavelmente pode ocorrer um controle muscular mais eficiente, permitindo uma melhora na otimização de tônus e, consequentemente, do equilíbrio (ESPINDULA et al., 2014).

Em um estudo que avalia de forma qualitativa e quantitativa 5 crianças com SD, onde busca-se avaliar as mudanças na postura dos membros inferiores dos praticantes, crianças de 12,60 anos de idade em média, foram submetidas a 20 sessões de equoterapia, sendo que cada sessão tem duração de 30 minutos e para a montaria foi utilizado manta e os pés do praticante fora do estribo. Foi utilizado o Software de Avaliação Postural (SAPO), onde os dados coletados na $1^{a}$ sessão e posteriormente na $20^{a}$ sessão, onde pode-se fazer a análise postural dos praticantes. Conclui-se que, o tratamento equoterapêutico pode modificar a postura e o alinhamento dos membros inferiores dos indivíduos, vendo que houve uma diminuição da anteversão pélvica, melhora no alinhamento da patela e diminuição da hiperextensão dos membros inferiores. Contudo não houve mudança significativa na distância entre as espinhas ilíacas ântero superiores (RIBEIRO et al., 2014).

'Vinícius Spagnol Regasson e Jaqueline Stefanello Garlet - Académicos do Curso de Fisioterapia da Universidade Franciscana - viniciusregasson@hotmail.com jaquelinegarlet15@outlook.com 
Pode-se denotar, então, que a equoterapia tem uma ampla eficiência nas pessoas com SD, Alves (2009) traz que não há só uma melhora física, mas também psíquica e social nos praticantes. Grande parte desses benefícios é influenciado pela andadura tridimensional do cavalo. Este movimento oscilatório é semelhante à marcha humana e permite a estimulação de diversos sistemas sensórias que favorecem o equilíbrio, a conscientização corporal, controle da posição do troco e da cabeça e recrutamento da musculatura abdominal e do troco como exemplo.

Para que o processo terapêutico tenha bom êxito a escolha do cavalo, do terreno e do material deve ser adequado para cada praticante (ALVES 2009). Dentre os estudos, os cuidados e pontos mais citados foram, um cavalo de boa saúde física e psíquica da raça Arabe e com temperamento dócil, com andadura a passo e engajamento de patas de forma a transpitar, antepistar e sobrepistar. O material mais utilizado na montaria foi a manta, e o posicionamento dos pé divergiu na literatura, sendo tanto com os pés fora dos estribo e uso continuo dos pés no estribo. Já para a seleção de terreno é citado a utilização do terreno de terra batida e terreno de pedra brita e cimento por Ribeiro et al. (2016), enquanto Copetti et al. (2007) relata a realização em áreas de grande diversidade de estímulos ambientais e que fossem adequadas para a realização das atividades.

\section{CONCLUSÃO}

Com base nas revisões bibliográficas, pode-se concluir que a equoterapia tem grande eficiência na melhora dos praticantes com SD. O tratamento equoterápico tem grande influência no ajuste tônico, nas reações de equilíbrio, melhora postural e do déficit de força dos membros inferiores e superiores, controle de tronco e normalização de tônus muscular e fortalecimento dos músculos. Além do mais, o próprio ato de cavalgar por si só gera estímulos ao praticante, salientando que é necessário fazer uma boa

1Vinícius Spagnol Regasson e Jaqueline Stefanello Garlet - Académicos do Curso de Fisioterapia da Universidade Franciscana - viniciusregasson@hotmail.com jaquelinegarlet15@outlook.com 
escolha do material de montaria na equoterapia para praticantes com SD, uma vez que estes apresentam hipotonia. Ademais, a prática da equoterapia propicia melhora na saúde mental e social dos praticantes.

Portanto, se faz necessário a realização de novas pesquisas na área da equoterapia, assim como estudos voltados a uma população amostral maior e mais heterogênea aos estudos já vistos, este campo carece de informações, o que ressalta a extrema importância de uma abordagem eficaz e que pode trazer benefícios para esse grande grupo, visando não somente uma abordagem competente para indivíduos com SD, mas também que possam beneficiar os praticantes em geral.

\section{REFERÊNCIAS}

BRASIL. Lei n 13.830, de 13 de maio de 2019. Jusbrasil, Brasília, 13 mai. 2019. Disponível em:< https://presrepublica.jusbrasil.com.br/legislacao/708039393/lei-13830-19> Acesso em 07/01/2021.

BRASIL. Resolução Nº. 348/2008 - Dispõe sobre o reconhecimento da EQUOTERAPIA como recurso terapêutico da Fisioterapia e da Terapia Ocupacional e dá outras providências. Coffito, DOU n. 63, Seção 1, p.150, 02/04/2008. Disponível em < https://www.coffito.gov.br/nsite/?p=3110\#: :text=RESOLU\%C3\%87\%C3\%830 \%20N\%C2\%BA.,Ocupacional\%20e\%20d\%C3\%A1\%20outras\%20provid\%C3\% AAncias> Acesso em 07/01/2021.

BEVILACQUA JUNIOR, D. E. et al. Avaliação da modulação autonômica em indivíduos com síndrome de Down na equoterapia. ConScientiae Saúde., Uberaba -MG , v.15, n.3, p:433-439. 433, jun. 2016.

UZUM, ALL. Equoterapia aplicação em distúrbios do equilíbrio. $1^{\text {a }}$ edição. Anápolis GO. Vetor, 1 janeiro de 2005.

1Vinícius Spagnol Regasson e Jaqueline Stefanello Garlet - Académicos do Curso de Fisioterapia da Universidade Franciscana - viniciusregasson@hotmail.com jaquelinegarlet15@outlook.com 
ESPINDULA, A. P.et al. Material de montaria para equoterapia em indivíduos com síndrome de down: estudo eletromiográfico. ConScientiae Saúde, São Paulo, v. 13, n. 3, p. 349-356, ago. 2014.

PROENÇA, R. F.M. et al. Benefícios da equoterapia no desenvolvimento motor da criança com síndrome de Down. Revisa.;v 9, n.3, p:357-61, Jul-Set. 2020. RIBEIRO, M.F.et al. Avaliação postural pré e pós-tratamento equoterapêutico em indivíduos com síndrome de Down. ConScientiae Saúde, Uberaba-MG, v.15, n.2, p:200-209, 2016.

SILVA, A.C. A UTILIZAÇÃO DA EQUOTERAPIA NO TRATAMENTO DA SÍNDROME DE DOWN: UMA REVISÃO SISTEMÁTICA. GTEC, Revista Gestão Tecnologia e Ciência, ano 2014, v. 3, n. 6, p. 68-77. TORQUATO, J.A. et al. A aquisição da motricidade em crianças portadoras de síndrome de Down que realizam fisioterapia ou praticam equoterapia. Fisioter. Mov., Curitiba, v. 26, n. 3, p. 515-524, jul. /set. 2013.

UZUM, ALL. Equoterapia aplicação em distúrbios do equilíbrio. $1^{\text {a }}$ edição. Anápolis GO. Vetor, 1 janeiro de 2005.

ALVES, Eveli Maluf Rodrigues. Prática em equoterapia: uma abordagem fisioterápica. São Paulo, SP: Atheneu, 2009. 87 p. ISBN 978-85-388-0049-1.

'Vinícius Spagnol Regasson e Jaqueline Stefanello Garlet - Académicos do Curso de Fisioterapia da Universidade Franciscana - viniciusregasson@hotmail.com jaquelinegarlet15@outlook.com 